\title{
DOE/MT/940/3--TZ
}

\section{A Distributed Activation Energy Model of Heterogeneous Coal Ignition}

\author{
Final Report \\ Project Period: \\ September 1, 1994 to August 31, 1995 \\ Submitted to:
US Department of Energy \\ Submitted by: \\ John C. Chen \\ Assistant Professor \\ Department of Mechanical Engineering
}

November 28, 1995

DISTRIBUTION OF THS DOCLMENT IS UNLIMITED

CLEARED BY 


\section{Introduction}

It is well known that coal is a highly inhomogeneous fuel made up of mostly carbon by mass. Usually, it also contains a substantial amount of mineral matter. These facts lead to the expectation, borne out by experimental observations, that in any single batch of pulverized coal, both chemical and thermophysical properties vary widely from particle to particle. It is also obvious that in any sample batch, there exists a wide distribution of particle sizes (diameters) - even after the sample is sized through standard wire-mesh sieves - and densities.

Experiments designed to measure kinetic rate constants of ignition of pulverized coals showed clearly that, for single particles or dilute suspensions, particle-to-particle variations due to reactivity and/or thermophysical properties are important. There exists ample evidence that the most important factor in interpreting these data is the existence of a variation in chemical reactivity in the sample. It is surprising, therefore, to note that all previous studies presumed that a single (average) activation energy is adequate to describe the ignition process. The equations formulated using this presumption are then correlated to the experimental measurements to infer the kinetic rate constants of ignition.

Our major objectives are to develop a model of heterogeneous ignition which allows for a distribution of activation energies, and to implement this model to interpret previously published data. It is our hypothesis that variations in chemical reactivity account for the experimental trends observed. Another objective of this project is to examine the effects of variations in thermodynamic and physical properties (e.g. specific heat, particle diameter, density) on data interpretation from previous ignition experiments.

\section{Objectives}

Our objectives for this project are:

1. To acquire a computer workstation on which to conduct this study;

2. Develop the Distributed Activation Energy Model of Heterogeneous Ignition;

3. Identify and gather all previous coal ignition studies, and tabulate those ignition data deemed reliable and useful; 
4. Apply our model to analyze previous data and determine ignition rate parameters;

5. Communicate our findings to the research community.

\section{Accomplishments}

All of the objectives of this project were achieved during the period of this grant. Specifically, we:

1. acquired a PC on which the modeling portion of this project was conducted, and presentations and reports were prepared;

2. identified and gathered all previous studies which reported ignition data under simulated pulverized-coal combustion conditions;

3. developed the Distributed Activation Energy Model of Heterogeneous Ignition, and applied the model to previously published data in the literature in order to extract kinetic rate constants of ignition;

4. communicated our findings to the coal-utilization community through conference presentations and refereed journal articles.

Each of the above four tasks will now be summarized.

\section{Task 1}

A laptop computer and various supplies and peripherals were acquired for this project. The equipment and supplies will continue to be used by the Principal Investigator for future projects.

\section{Task 2}

Listed below are those studies. which reported ignition data on pulverized coals.

1. Bandyopadhyay, S. and Bhaduri, D. Combust. Flame, 18:411 (1972).

2. Annamalai, K. and Durbetaki, P. Combust. Flame, 29:193 (1977).

3. Karcz, H., Kordylewski, W., and Rybak, W. Fuel, $59: 799$ (1980).

4. Wall, T.F. and Gururajan, V.S. Combust. Flame, 66:151 (1986).

5. Essenhigh, R.H., Mahendra, K.M., and Shaw, D.W. Combust. Flame, 77:3 (1989).

6. Gururajan, V.S., Wall, T.F., Gupta, R.P., and Truelove, J.S. Combust. Flame, 81:119 (1990). 
7. Tomeczek, J. and Wojcik, J. Twenty-Tbird Symposium (International) on Combustion, The Combustion Institute, Pittsburgh, 1990, p. 1163.

8. Wall, T.F., Gupta, R.P., Gururajan, V.S., and Zhang, D. Fuel, 70:1011 (1991).

9. Fu, W. and Zeng, T. Combust. Flame, 88:413 (1992).

10. Zhang, D., Wall, T.F., Harris, D.J., Smith, I.W., Chen, J., and Stanmore, B.R. Fuel, 71:1239 (1992).

11. Phuoc, T.X., Mathur, M.P., and Ekmann, J.M. Combust. Flame, 93:19 (1993).

12. Boukara, R., Gadiou, R., Gilot, P., Delfosse, L., and Prado, G. Twenty-Fourth Symposium (International) on Combustion, The Combustion Institute, Pittsburgh, 1993, p.1127.

\section{Task 3}

A detailed summary of the research results can be found beginning on page 4 of this document.

\section{Task 4}

Our results have been presented at the following conferences:

-Third Annual Historically Black Colleges and Universities/Private Sector/Energy

Research and Development Technology Transfer Symposium, Clark-Atlanta

University, April 27-29, 1995;

-Twelfth Annual International Pittsburgh Coal Conference, Pittsburgh, PA, September 11-15, 1995;

A third presentation, at the 1995 Technical Meeting of the Eastern States Section/Combustion Institute in October 1995, was withdrawn by the Principal Investigator due to a family emergency.

One manuscript, entitled "Distributed Activation Energy Model of Heterogeneous Coal Ignition," was submitted to and accepted for publication by the journal, Combustion and Flame. We expect publication of the article sometime in early 1996. A second manuscript is currently being prepared, and will be submitted upon completion for publication and presentation at the Twenty-Sixth International Symposium on Combustion, to be held in August, 1996, in Naples, Italy. Acceptance by this symposium would represent a refereed publication since a minimum of three out of four reviewers must approve of the paper. 


\section{Summary of Research Results}

\section{ABSTRACT}

We present a model which simulates the conventional tube-furnace experiment used for ignition studies. The Distributed Activation Energy Model of Ignition accounts for particle-toparticle variations in reactivity by having a single preexponential factor and a Gaussian distribution of activation energies among the particles. The results show that the model captures the key experimental observations, namely (1) the linear increase in ignition frequency with increasing gas temperature, and (2) the variation of the slope of the ignition frequency with oxygen concentration. It is shown that adjustments to the model parameters permit a good fit to experimental data. 


\section{NOMENCLATURE}

$A_{0}$ preexponential factor in Arrhenius rate constant of ignition, $\mathrm{kg} \mathrm{m}^{-2} \mathrm{~s}^{-1}$

d diameter, $\mathrm{m}$

$\mathrm{E} \quad$ activation energy of ignition, $\mathrm{kJ} \mathrm{mol}^{-1}$

$\mathrm{E}_{0} \quad$ mean of Gaussian distribution, $\mathrm{kJ} \mathrm{mol}^{-1}$

h convective heat transfer coefficient, $\mathrm{W} \mathrm{m}^{-2} \mathrm{~K}$

$\mathrm{H}_{\mathrm{c}} \quad$ heat of reaction, $\mathrm{J} \mathrm{kg}^{-1}$

$\mathrm{k} \quad$ conductivity, $\mathrm{W} \mathrm{m}^{-1} \mathrm{~K}$

n reaction order of ignition with respect to oxygen, -

Q heat generated or heat loss, $\mathrm{W}$

$\mathrm{R}$ universal gas constant, $8.314 \times 10^{-3} \mathrm{~kJ} \mathrm{~mol}^{-1} \mathrm{~K}^{-1}$

$\mathrm{S} \quad$ external surface area of particle, $\mathrm{m}^{2}$

$\mathrm{T}$ temperature, $\mathrm{K}$

y molar ratio of $\mathrm{CO}$ to $\mathrm{CO}_{2}$

\section{Greek symbols}

$\chi_{\mathrm{O}_{2}} \quad$ oxygen mole fraction at particle surface, -

$\varepsilon \quad$ emissivity of coal, -

$\sigma_{\mathrm{b}} \quad$ Stefan-Boltzmann constant, $5.67 \times 10^{-8} . \mathrm{W} \mathrm{m}^{-2} \mathrm{~K}^{-4}$

$\sigma \quad$ standard deviation of Gaussian distribution, $\mathrm{kJ} \mathrm{mol}^{-1}$

\section{Subscripts}

conv convection

g gas

$\mathrm{p} \quad$ particle

rad radiation 


\section{INTRODUCTION}

Numerous experiments have been conducted over the past three decades to study the ignition of pulverized coals under conditions relevant to utility boilers. The conventional experiment is based on one developed by Cassel and Liebman [1], and consists of a tube furnace containing a heated mixture of $\mathrm{O}_{2}$ and inert gas. The temperature of the furnace, and hence the gas, is the independent variable in this arrangement. The experiment is conducted by dropping a small batch of presized coal particles into the hot gas and observing visually for a flash of light which signals ignition. In such an experiment the particle concentration is typically low enough that each particle can be considered to behave independently of all others. The furnace temperature is then decreased and the experiment is repeated to determine the minimum gas temperature (or the critical gas temperature) at which ignition occurs. This condition is termed critical ignition. Finally, the particle size or the $\mathrm{O}_{2}$ concentration is changed and, again, the critical ignition condition is found for the new operating condition.

\section{THEORY OF HETEROGENEOUS IGNITION}

Essenhigh et al. [2] describe in detail the theory of heterogeneous ignition - that is, ignition which occurs at the solid-gas interface. For a coal particle exposed to an oxidizing environment, ignition is determined by the balance between heat generation at and heat loss from the particle surface. The heat loss from the surface of a particle at temperature $T_{p}$ is the sum of the losses due to convection and radiation:

$$
\begin{aligned}
Q_{\text {loss }} & =Q_{\text {loss,conv }}+Q_{\text {loss, rad }} \\
& =b S\left(T_{p}-T_{g}\right)+\varepsilon \sigma_{b} S\left(T_{p}^{4}-T_{g}^{4}\right) .
\end{aligned}
$$


Equation 1 assumes that the surroundings involved in radiation exchange are in thermal equilibrium with the gas.

The radiative loss term is relatively unimportant until the particle temperature exceeds $\sim 1500 \mathrm{~K}$. For the convective-loss term, we assume that Nusselt number equals two, as is appropriate for very small particles, which leads to $h=2 k_{g} / d_{p}$. Thus, Eq. 1 can be rewritten, on a per-external-surface-area basis, as:

$$
\frac{Q_{\text {loss }}}{S}=\frac{2 k_{g}}{d_{p}}\left(T_{p}-T_{g}\right)+\varepsilon \sigma_{b}\left(T_{p}^{4}-T_{g}^{4}\right)
$$

The gas thermal conductivity, $k_{g}$, in the boundary layer around a heated particle is given by a linear fit to the conductivity of air over the temperature range of $300-2000 \mathrm{~K}$ :

$$
k_{g}=7.0 \times 10^{-5}\left[\frac{T_{p}+T_{g}}{2}\right] \frac{\mathrm{W}}{\mathrm{m} \mathrm{K}} .
$$

Equation 3 represents an approximation for the conductivity evaluated at the mean of the freestream and particle-surface temperatures.

The heat generated by a spherical carbon particle undergoing oxidation on its external surface is given by the kinetic expression:

$$
\frac{Q_{g e n}}{S}=H_{c} \chi_{o_{2}}^{n} A_{o} \exp \left[\frac{-E}{R T_{p}}\right] .
$$

Diffusion effects are neglected since, at the relatively low particle temperatures of pulverizedcoal ignition, the oxidation reaction is kinetically controlled.

At the critical ignition condition, the following two conditions are satisfied [2]:

$$
Q_{g e n}=Q_{\text {loss }}, \text { and }
$$




$$
\frac{d Q_{g e n}}{d T_{p}}=\frac{d Q_{\text {loss }}}{d T_{p}}
$$

For the purpose of this study, it is presumed that certain of the variables in Eqs. 2 and 4 are known a priori $\left(\mathrm{H}_{\mathrm{c}}, \mathrm{A}_{\mathrm{o}}, \mathrm{n}, \mathrm{d}_{\mathrm{p}}\right.$ and $\left.\varepsilon\right)$, or are fixed by the experimental conditions $\left(\mathrm{T}_{\mathrm{g}}\right.$ and $\chi_{\mathrm{O}_{2}}$ ); the values of these variables used for the base case (described below) are shown in Table 1. The remaining unknowns, $\mathrm{T}_{\mathrm{p}}$ and $\mathrm{E}$, can then be determined by the simultaneous solution of Eqs. 5 and 6; the relation of these two parameters to $T_{g}$ for the base case is shown in Fig. 1. $T_{p}$ determined in this manner represents the critical ignition temperature, while $\mathrm{E}$ can be interpretted as the critical (or maximum) activation energy that a particle may have and still ignite under the given conditions. A detailed expansion of Eqs. 5 and 6 is given in the Appendix.

\section{MODEL FORMULATION}

Figure 2 shows typical data [3] obtained from an ignition experiment conducted by varying the gas temperature while holding all other conditions constant. The data shown was obtained by conducting the experiment as described earlier except that, at each temperature, 10 to 20 tests for ignition were repeated to obtain a frequency or probability of ignition. The figure shows that ignition frequency increases approximately linearly with gas temperature, and this is inconsistent with heterogeneous ignition theory described above. If all particles of a coal sample used in an experiment have the same reactivity - i.e. they are described by a common Arrhenius rate constant in Eq. 4 - then the data would show an ignition frequency of zero percent until the critical gas temperature, corresponding to that at the critical ignition condition, is reached. At any gas temperature above this, the ignition frequency would be 
$100 \%$. Note that the observed ignition frequency trend is not an artifact of the experiment; this same behavior is reported from a variety of ignition experiments $[4,5,6]$ including thermogravimetric analyzers and laser-based studies.

One reason for why ignition frequency should increase gradually with increasing gas temperature is somewhat obvious: Within any sample of coal, there exists a distribution of reactivity among the particles. Thus, in the conventional ignition experiment, in which a batch of perhaps a few hundred particles of a sample is dropped into the furnace, there is an increasing probability (or frequency) that at least one particle has a reactivity which meets or exceeds the critical ignition condition set forth in Eqs. 5 and 6 . Of course, there exist other variations among the particles within a sample, such as particle size and specific heat. Variation in size alone, however, cannot account for another experimental observation (described later), although it could account for the observed increase in ignition frequency with gas temperature. A distribution in specific heat would only affect the rate at which a particle attains its equilibrium temperature, but would not change this value or the reactivity. Perhaps other variations could cause the observed behavior of ignition frequency. However, it is our premise that the distribution in reactivity dominates all other variations, and therefore accounts for the observed behavior.

The Distributed Activation Energy Model of Ignition (DAEMI) models the conventional ignition experiment by allowing for the particles within the coal sample to have a distribution of reactivity. We prescribe that all the particles have the same properties, including the preexponential factor in the Arrhenius rate constant describing their ignition reactivity, and that their activation energy is distributed according to the Gaussian (or normal) distribution: 


$$
f(E)=\frac{1}{\left(2 \pi \sigma^{2}\right)^{0.5}} \exp \left[\frac{-\left(E-E_{o}\right)^{2}}{2 \sigma^{2}}\right]
$$

where $\mathrm{E}_{0}$ is the mean and $\sigma$ is the standard deviation of the distribution. The expression

$$
\int_{E}^{E+\Delta E} f(E) d E
$$

describes the frequency or probability that particles within a sample have an activation energy in the range $\mathrm{E}$ to $\mathrm{E}+\Delta \mathrm{E}$. Accordingly, the distribution satisfies the condition that $\int_{-\infty}^{\infty} f(E) d E=1$

The DAEMI divides a prescribed distribution into discrete energy intervals of $\triangle E=3 \mathrm{~kJ}$ mol $^{-1}$, and considers only the energy range of $E_{0}-3 \sigma$ to $E_{0}+3 \sigma$, rather than $-\infty$ to $+\infty$. The latter simplification still covers $99.73 \%$ of the distribution. The model then calculates the frequency of being in each of these intervals by numerically integrating Eq. 8 for each of the intervals.

An ignition experiment is modeled by assuming that $10^{5}$ particles are in the initial sample, and that they are distributed among the various $\Delta \mathrm{E}$ intervals according to the calculated frequency for each interval. Each experimental "run" under a given set of conditions is conducted on a batch of 100 randomly selected particles from the sample, keeping in mind that no particle can be selected more than once. Whether or not ignition occurs for a run is determined by the particle in the batch with the lowest activation energy. If this particle's reactivity equals or exceeds that determined by the critical ignition condition (that is, its activation energy is less than or equal to the critical energy determined by solution of Eqs. 5 and 6), the batch is defined to be ignited. This is consistent with our observation [6] 
that single-particle ignition is discernible to the eye, and certainly to a photon detector. This procedure is repeated 20 times at each condition, just as in actual experiments, to determine an ignition frequency at this condition. Finally, the gas temperature is varied several times and, each time, 20 runs are conducted.

\section{RESULTS AND DISCUSSION}

Figure 3 shows model results of ignition frequency versus gas temperature for one hypothetical sample for which $E_{0}=120 \mathrm{~kJ} \mathrm{~mol}^{-1}, \sigma=16 \mathrm{~kJ} \mathrm{~mol}^{-1}$ and $A_{0}=500 \mathrm{~kg} \mathrm{~m}^{-2} \mathrm{~s}^{-1}$. The other parameters of this base case calculation are listed in Table 1 . It is obvious that the DAEMI exhibits the experimental characteristic of increasing ignition frequency with increasing gas temperature. As stated earlier, this is expected since an increase in gas temperature leads to an increase in the maximum activation energy which a particle can have and still be ignitable (see Fig. 1), and therefore to an increased probability of having at least one particle which is reactive enough to ignite.

Figures 4 and 5 display the effects of varying $E_{o}$ and $\sigma$, respectively, on the DAEMI. An increase in $E_{0}$, which shifts the Gaussian distribution to higher energies (Fig. 4a), has the effect of shifting the ignition-frequency data to higher gas temperatures (Fig. 4b). This is the expected behavior since a representative batch from the higher $E_{0}$ sample contains, on average, particles with higher activation energies which require a higher temperature to induce ignition. Note that $E_{o}$ has no discernible effect on the slope of the data in Fig. $4 \mathrm{~b}$.

Figure 5 shows that an increase in the standard deviation $(\sigma)-$ the spread of the Gaussian distribution (Fig. 5a) - has two effects: a shift of the ignition frequency to lower temperatures, and a slower rise of ignition frequency with gas temperature (Fig. 5b). These 
findings are somewhat unexpected since the average activation energy $\left(E_{0}\right)$ is the same for both samples, and they result from the use of a small batch (100 particles) in each run. The shift to lower temperatures is due to the fact that, statistically, the most reactive particle in the larger $\sigma$ batch will have a lower activation energy than the most reactive particle from the smaller $\sigma$ batch because of its wider spread in distribution. Thus, this higher reactivity allows for ignition to occur at lower temperatures. The wider spread and small batch also cause the slower approach to $100 \%$ ignition frequency since the probability of having a batch containing only relatively higher energy particles is increased, which requires higher gas temperatures until all runs result in ignition. Clearly, by adjusting the two parameters of the Gaussian distribution (Eq. 7), $E_{0}$ and $\sigma$, the DAEMI can be fitted to ignition data such as those in Fig. 2, provided that accurate values for the parameters shown in Table 1 are available.

The DAEMI in its present form fails to capture a second experimental characteristic, namely the change in slope of the ignition frequency data with oxygen concentration, as shown in Fig. 6. The lines shown are linear regressions of experimental data from Ref. [3]. (The data points are explained below.) In fact, the DAEMI shows a very weak dependence on oxygen concentration (not shown), so the question remains as to what parameter has not been, or is incorrectly, accounted for. The obvious candidate is the reaction order, $n$, which must vary with $\chi_{\mathrm{O}_{2}}$ in order to cause the observation. However, we can think of no fundamental basis for this behavior.

A second, less obvious parameter is the heat of reaction, $\mathrm{H}_{c}$, of ignition. So far in the presentation of the DAEMI, it has been assumed that the product of coal ignition is $\mathrm{CO}$, as shown by the value for $\mathrm{H}_{c}$ in Table 1 . However, it is well known that the product of carbon 
oxidation is both $\mathrm{CO}$ and $\mathrm{CO}_{2}$, with the relative amounts dependent on both temperature and oxygen partial pressure $[7,8]$. The significance of this is that their heats of reaction are vastly different:

$$
\begin{aligned}
& C+\frac{1}{2} \mathrm{O}_{2} \rightarrow \mathrm{CO} ; \mathrm{H}_{\mathrm{C}, \mathrm{CO}}^{\prime}=9,210 \frac{\mathrm{kJ}}{\mathrm{kg} \mathrm{C}} \\
& \mathrm{C}+\mathrm{O}_{2} \rightarrow \mathrm{CO}_{2} ; \mathrm{H}_{\mathrm{C}, \mathrm{CO}_{2}}^{\prime}=32,790 \frac{\mathrm{kJ}}{\mathrm{kg} \mathrm{C}}
\end{aligned}
$$

Thus, the value of $\mathrm{H}_{c}$ in Eq. 4 is dependent on the relative amounts of $\mathrm{CO}$ and $\mathrm{CO}_{2}$ formed during ignition, and is given by the expression:

$$
H_{C}=\frac{y}{y+1} H_{C, C O}^{\prime}+\frac{1}{y+1} H_{C, \mathrm{CO}_{2}}^{\prime}
$$

where $y \doteq \frac{\mathrm{mol} \mathrm{CO}}{\mathrm{mol} \mathrm{CO}_{2}}$. We have assumed here that energy released by any $\mathrm{CO}$ which oxidizes as it diffuses away from the particle surface does not affect the ignition.

This modification to the.DAEMI should now show the experimental trend. Measurements $[7,8]$ show that at higher particle temperature (which results from higher $\mathrm{T}_{\mathrm{g}}$ ), the molar ratio $\mathrm{CO} / \mathrm{CO}_{2}$ increases and consequently $\mathrm{H}_{\mathrm{c}}$, the amount of heat released during ignition, decreases. Therefore, the result of a set of runs conducted at a decreased oxygen level not only shifts the ignition frequency data to higher $\mathrm{T}_{\mathrm{g}}$ (a direct result of the decreased $\chi_{\mathrm{O}_{2}}$ ) but also reduces the slope of the rise (an indirect result because of the decreased $\mathrm{H}_{\mathrm{c}}$ ).

Direct measurements of the $\mathrm{CO} / \mathrm{CO}_{2}$ ratio have been made by Du et al. [7] in a thermogravimetric analyzer (TGA) using soot as the carbon material. Measurements were made over the temperature range of $667-873 \mathrm{~K}$ and oxygen partial pressures from 0.1 to 1 atm. The results at an oxygen partial pressure of $0.21 \mathrm{~atm}$ are correlated by the expression: 


$$
\frac{\mathrm{mol} \mathrm{CO}}{\mathrm{mol} \mathrm{CO}_{2}}=59.95 \exp \left[\frac{-3214}{T_{p}(K)}\right]
$$

This correlation is incorporated into the DAEMI and the model results are shown in Fig. 7. Notice that the model now clearly possesses the desired characteristic. Furthermore, it captures both the decrease in the slope of the ignition frequency with decreasing oxygen concentration, and the slow rate of the slope's decrease until low oxygen concentrations, showing the nonlinear behavior with $\chi_{\mathrm{O}_{2}}$ displayed in experimental data (Fig. 6).

By adjusting the mean, the standard deviation and the reaction order, $n$, of the base case, this current version of DAEMI can be fit to the experimental data of Fig. 6. (The particle diameter has also been changed to $83.0 \mu \mathrm{m}$ to match the mean of the sample used in Ref. [3].) The model results using $\mathrm{E}_{\mathrm{o}}=84.0 \mathrm{~kJ} \mathrm{~mol}^{-1}, \sigma=4.0 \mathrm{~kJ} \mathrm{~mol}^{-1}$ and $\mathrm{n}=0.4$ are plotted as data points in Fig. 6 over the regression lines and show that a satisfactory fit is achieved with minimal effort in parameter adjustment, despite the uncertainties in the values of other parameters. (Because of the small value of $\sigma$ used, the energy intervals into which the distribution is divided was decreased from $3 \mathrm{~kJ} \mathrm{~mol}^{-1}$ to $1 \mathrm{~kJ} \mathrm{~mol}^{-1}$ to obtain these results.) While the model in its current form can certainly be used to extract ignition rate constants from the myriad of experimental data in the literature, such an effort would be futile until values for the remaining variables (e.g. $A_{0}, n, y\left(T_{p}\right)$ ) are known with more certainty.

Although we have assumed in this study that pulverized-coal ignition occurs heterogeneously without influence from any volatile matter that may be present, and even though the results closely fit the experimental data, it cannot be said that the DAEMI confirms that ignition is purely a heterogeneous process. Very few models of homogeneous ignition 
have been presented, and none have been tested against the available experimental data because of the inherent difficulty and uncertainty in modeling devolatilization and the combined solid- and gas-phase reactions.

\section{CONCLUSIONS}

The DAEMI has been formulated to model conventional coal-ignition experiments. It accounts for particle-to-particle variations in reactivity within a sample by allowing for a distribution in activation energies among the particles and a single preexponential factor.

The model captures the main characteristics of actual experiments, namely (1) the gradual increase in ignition frequency with increasing gas temperature and (2) the variation of the slope of the ignition frequency with $\mathrm{O}_{2}$ concentration. Finally, it has been shown that adjustments to the model parameters can be used to fit experimental data and extract reaction rate constants. 


\section{REFERENCES}

1 Cassel, H.M. and Liebman, I. Combust. Flame, 3:467-475 (1959).

2 Essenhigh, R.H., Mahendra, K.M., and Shaw, D.W. Combust. Flame, 77:3-30 (1989).

3 Zhang, D., Wall, T.F., Harris, D.J., Smith, I.W., Chen, J., and Stanmore, B.R. Fuel, 71:1239-1246 (1992).

4 Tomeczek, J., and Wojcik, J. Twenty-Third Symposium (International) on Combustion, The Combustion Institute, Pittsburgh, 1990, pp. 1163-1167.

5 Boukara, R., Gadiou, R., Gilot, P., Delfosse, L., and Prado, G. Twenty-Fourth Symposium (International) on Combustion, The Combustion Institute, Pittsburgh, 1993, pp. 1127-1133.

6 Chen, J., Taniguchi, M., Narato, K. and Ito, K. Combust. Flame, 97:107-117 (1994).

7 Du, Z., Sarofim, A.F., and Longwell, J.P. Energy and Fuels, 5:214-221 (1991).

8 Mitchell, R.E., Kee, R.J., Glarborg, P., and Coltrin, M.E. Twenty-Third Symposium (International) on Combustion, The Combustion Institute, Pittsburgh, 1990, pp. 11691176. 


\section{APPENDIX}

\section{Expansion of Eqs. 5 and 6}

In order to determine the critical ignition temperature of the particle, $T_{p}$, and critical activation energy, E, Eqs. 5 and 6 are solved simultaneously. $Q_{\text {gen }}$ and $Q_{\text {loss }}$ are given in Eqs. 2 and 4, and lead to the following derivatives with respect to temperature:

$$
\begin{gathered}
\frac{d Q_{g e n}}{d T_{p}}=S H_{c} \chi_{o_{2}}^{n} A_{o} \exp \left[\frac{-E}{R T_{p}}\right]\left(\frac{E}{R T_{p}^{2}}\right) . \\
\frac{d Q_{\text {loss }}}{d T_{p}}=\frac{2 k_{g}}{d_{p}} S+4 \varepsilon \sigma_{b} S T_{p}^{3} .
\end{gathered}
$$

Note that the neglect of the $\mathrm{T}_{\mathrm{p}}$ dependence in $\mathrm{k}_{\mathrm{g}}$ introduces a small error in Eq. 13.

Following Eq. 6, we set Eq. 12 equal to Eq. 13 and solve for the quantity $\frac{E}{R T_{p}}$ :

$$
\frac{E}{R T_{p}}=\frac{\frac{2 k_{g}}{d_{p}} T_{p}+4 \varepsilon \sigma_{b} T_{p}^{4}}{H_{c} \chi_{O_{2}}^{n} A_{o} \exp \left[\frac{-E}{R T_{p}}\right]}
$$

The denominator is recognized to be $\mathrm{Q}_{\text {gen }} / \mathrm{S}$ (Eq. 4), which by Eq. 5 is also $\mathrm{Q}_{\mathrm{loss}} / \mathrm{S}$ (Eq. 2). Thus Eq. 14 can be rewritten as:

$$
\frac{E}{R T_{p}}=\frac{\frac{2 k_{g}}{d_{p}} T_{p}+4 \varepsilon \sigma_{b} T_{p}^{4}}{\frac{2 k_{g}}{d_{p}}\left(T_{p}-T_{g}\right)+\varepsilon \sigma_{b}\left(T_{p}^{4}-T_{g}^{4}\right)}
$$

This relation for $\frac{E}{R T_{p}}$ is substituted into the expression $Q_{g e n}-Q_{\text {loss }}=0$ to obtain a function $\mathrm{F}$ which is a function of $T_{p}$ only: 


$$
\begin{gathered}
F\left(T_{p}\right)=Q_{g e n}-Q_{\text {loss }} \\
=H_{c} \chi_{O_{2}}^{n} A_{o} \exp \left[\frac{\frac{-2 k_{g}}{d_{p}} T_{p}-4 \varepsilon \sigma_{b} T_{p}^{4}}{\frac{2 k_{g}}{d_{p}}\left(T_{p}-T_{g}\right)+\varepsilon \sigma_{b}\left(T_{p}^{4}-T_{g}^{4}\right)}\right]-\frac{2 k_{g}}{d_{p}}\left(T_{p}-T_{g}\right)-\varepsilon \sigma_{b}\left(T_{p}^{4}-T_{g}^{4}\right)=0 .
\end{gathered}
$$

The reasonable root of $F\left(T_{p}\right)$ corresponds to the critical ignition temperature of the particle, and substitution of this value into Eq. 15 produces the critical activation energy at the critical ignition condition.

\section{DISCLAIMER}

This report was prepared as an account of work sponsored by an agency of the United States Government. Neither the United States Government nor any agency thereof, nor any of their employees, makes any warranty, express or implied, or assumes any legal liability or responsibility for the accuracy, completeness, or usefulness of any information, apparatus, product, or process disclosed, or represents that its use would not infringe privately owned rights. Reference herein to any specific commercial product, process, or service by trade name, trademark, manufacturer, or otherwise does not necessarily constitute or imply its endorsement, recommendation, or favoring by the United States Government or any agency thereof. The views and opinions of authors expressed herein do not necessarily state or reflect those of the United States Government or any agency thereof. 


\section{TABLE CAPTIONS}

Table 1: Values of parameters used in the base case of the model.

\section{FIGURE CAPTIONS}

Fig. 1: Relation of critical ignition temperature (dashed line) and critical activation energy (solid line) to gas temperature, $\mathrm{T}_{\mathfrak{g}}$, for base case listed in Table 1 .

Fig. 2: Typical data from a conventional ignition experiment showing the relation between ignition frequency (or probability) and gas temperature for a bituminous coal. Data extracted from Ref. [3].

Fig. 3: Results from Distributed Activation Energy Model of Ignition (DAEMI) for base case (Table 1).

Fig. 4: DAEMI results showing the effect of $E_{0}$ on ignition frequency. (a) Solid-colored distribution corresponds to $\mathrm{E}_{0}=110 \mathrm{~kJ} \mathrm{~mol}^{-1}$, and the distribution shown in outline corresponds to $E_{0}=120 \mathrm{~kJ} \mathrm{~mol}^{-1}$; all other parameters are as listed in Table 1. (b) Ignition frequency data for $E_{0}=110 \mathrm{~kJ} \mathrm{~mol}^{-1}(\square)$ and $E_{0}=120 \mathrm{~kJ} \mathrm{~mol}^{-1}(O)$.

Fig. 5: DAEMI results showing the effect of $\sigma$ on ignition frequency. (a) Solid-colored distribution corresponds to $\sigma=20 \mathrm{~kJ} \mathrm{~mol}^{-1}$, and the distribution shown in outline corresponds to $\sigma=12 \mathrm{~kJ} \mathrm{~mol}^{-1}$; all other parameters are as listed in Table 1. (b) Ignition frequency data for $\sigma=20 \mathrm{~kJ} \mathrm{~mol}^{-1}(\boldsymbol{M})$ and $\sigma=12 \mathrm{~kJ} \mathrm{~mol}^{-1}(\Delta)$.

Fig. 6: Linear regressions of experimental data from Ref. [3] (shown as solid lines), showing the effect of free-stream oxygen concentration on ignition of a high-volatile bituminous coal of diameters $75-90 \mu \mathrm{m}$. The data points represent results from the DAEMI, including the modification to account for the production of both $\mathrm{CO}$ and $\mathrm{CO}_{2}$ and adjustments to the base case values for $\mathrm{E}_{\mathrm{o}}, \sigma$ and $\mathrm{n}$, as described in the text.

Fig. 7: DAEMI results, including the modification to account for the production of both $\mathrm{CO}$ and $\mathrm{CO}_{2}$, showing the effect of oxygen concentration on ignition frequency. The solid lines are linear regressions of the data points. 


\begin{tabular}{cccl} 
variable & value & units & \multicolumn{1}{c}{ remarks } \\
\hline $\mathrm{A}_{\mathrm{o}}$ & 500 & $\mathrm{~kg} \mathrm{~m}^{-2} \mathrm{~s}^{-1}$ & arbitrarily chosen to illustrate model \\
$\mathrm{d}_{\mathrm{p}}$ & 100 & $\mu \mathrm{m}$ & $\begin{array}{l}\text { arbitrarily chosen to illustrate model } \\
\mathrm{E}_{\mathrm{o}}\end{array}$ \\
$\mathrm{H}$ & 120 & $\mathrm{~kJ} \mathrm{~mol}^{-1}$ & arbitrarily chosen to illustrate model \\
$\mathrm{n}$ & 9210 & $\mathrm{~kJ} \mathrm{~kg}^{-1}$ & for the reaction $\mathrm{C}+1 / 2 \mathrm{O}_{2} \rightarrow \mathrm{CO}$ \\
$\sigma$ & 1.0 & - & arbitrarily chosen to illustrate model \\
$\varepsilon$ & 16.0 & $\mathrm{~kJ} \mathrm{~mol}^{-1}$ & arbitrarily chosen to illustrate model \\
& 0.8 & - & arbitrarily chosen to illustrate model
\end{tabular}


Critical Ignition Temperature (K)

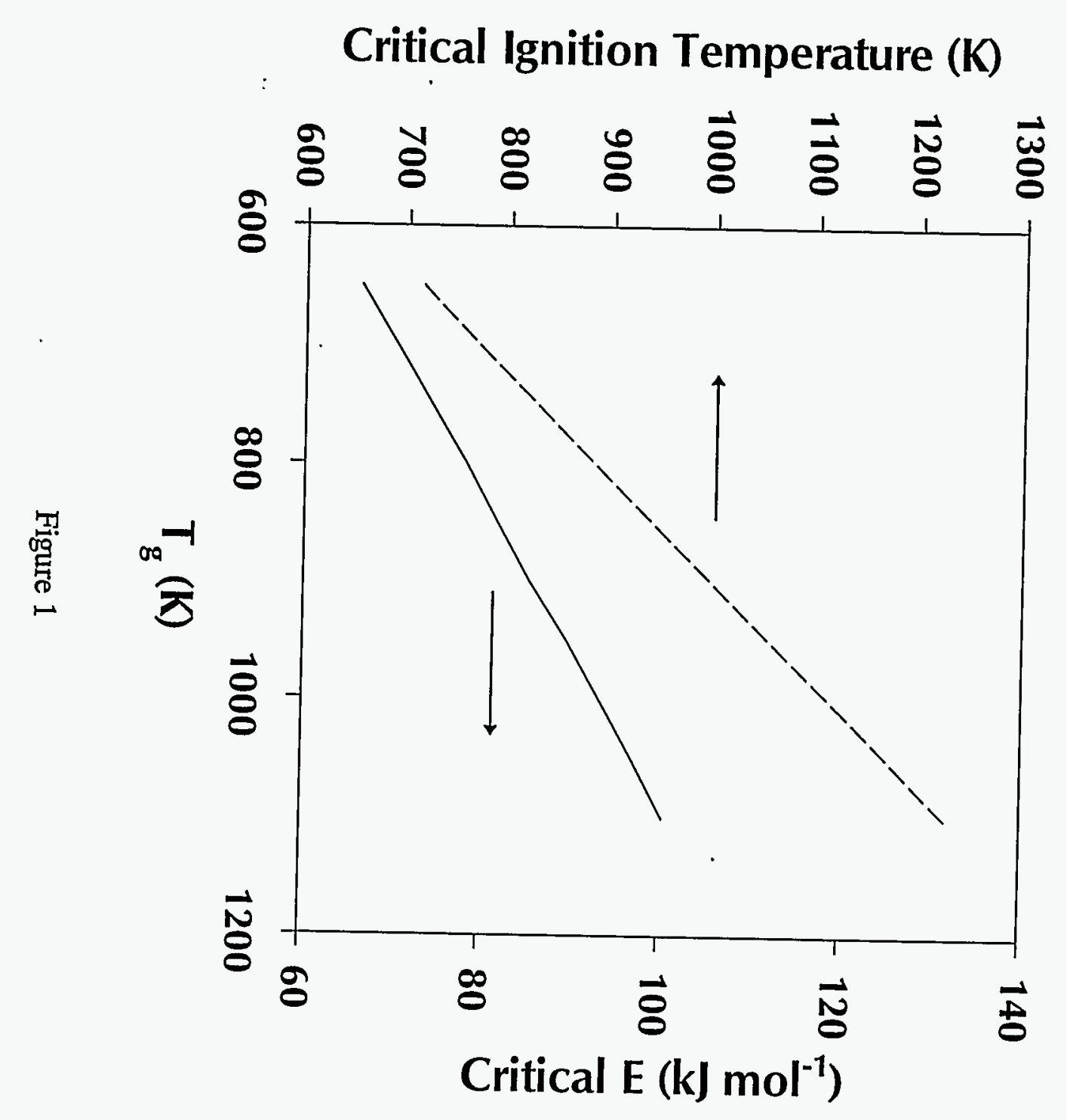




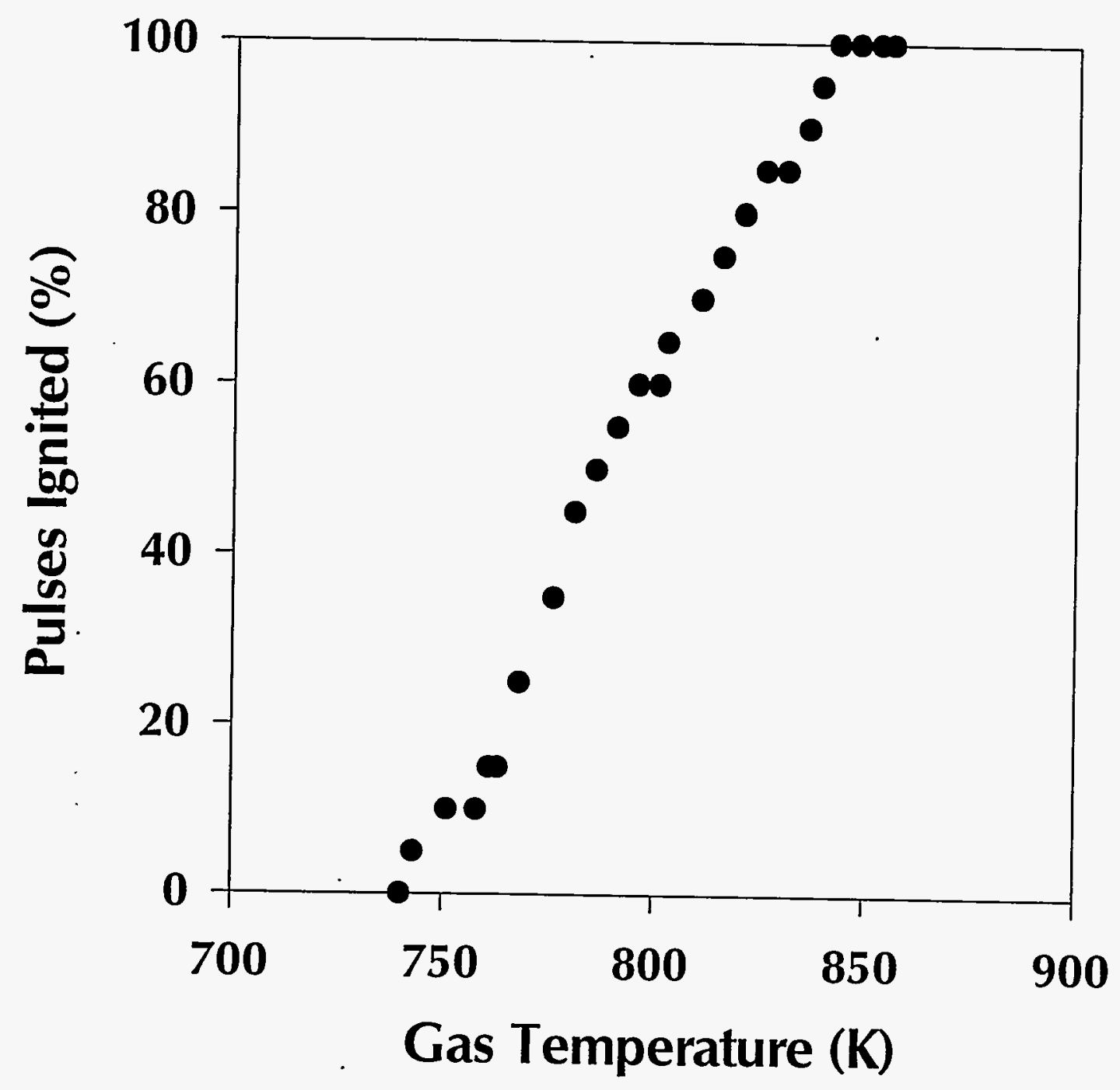

Figure 2 


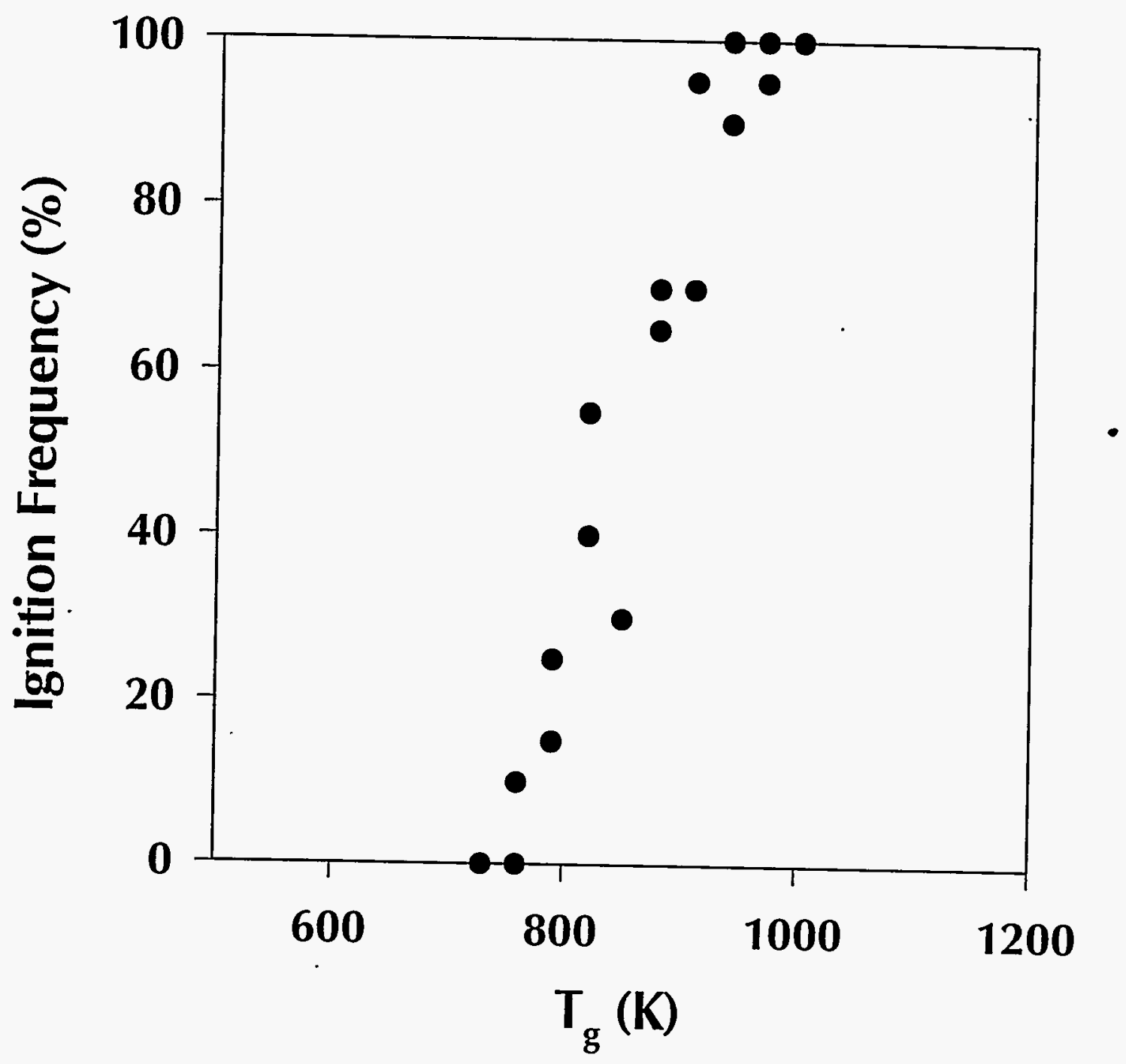

Figure 3 

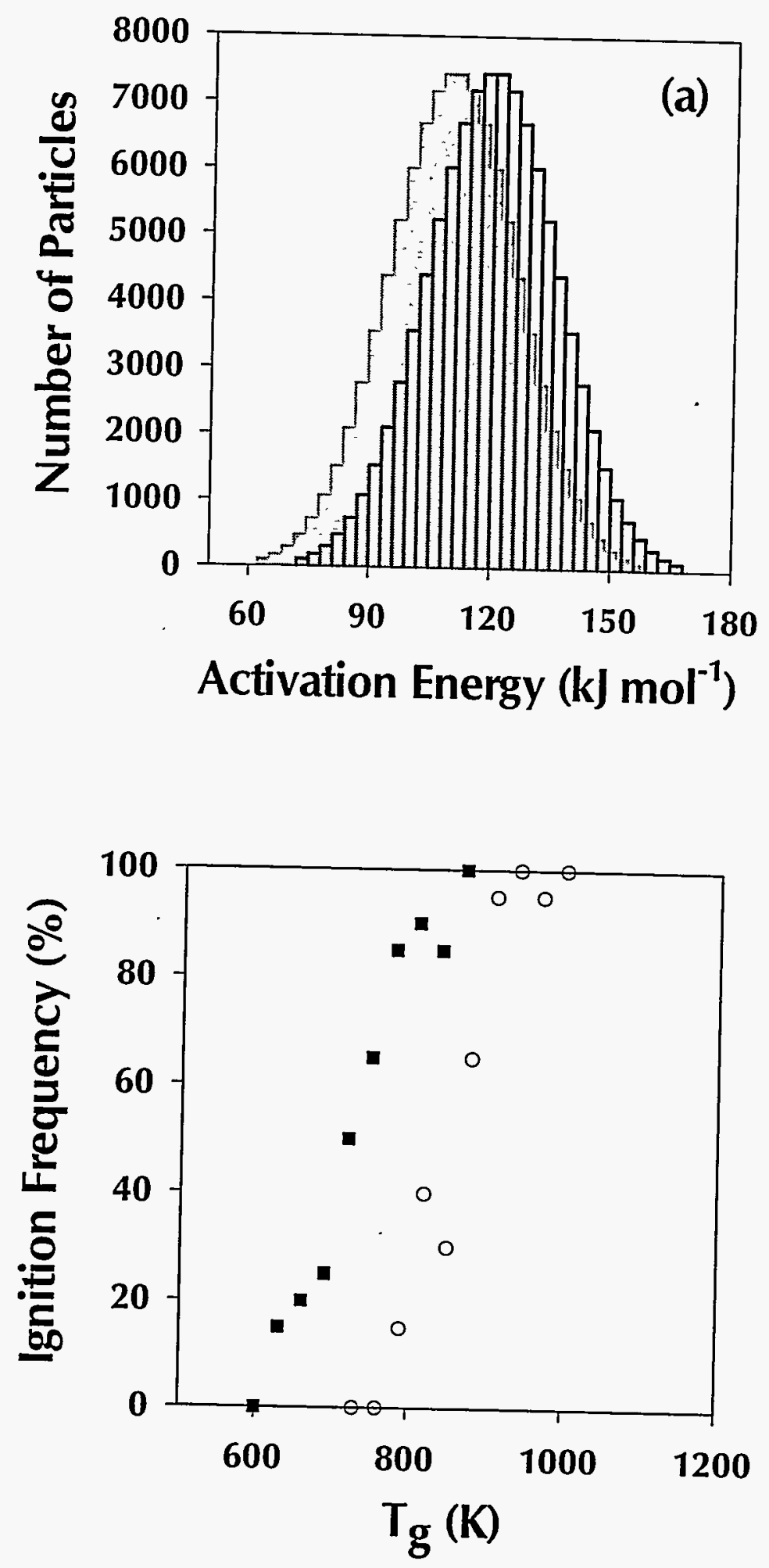

Figure 4 

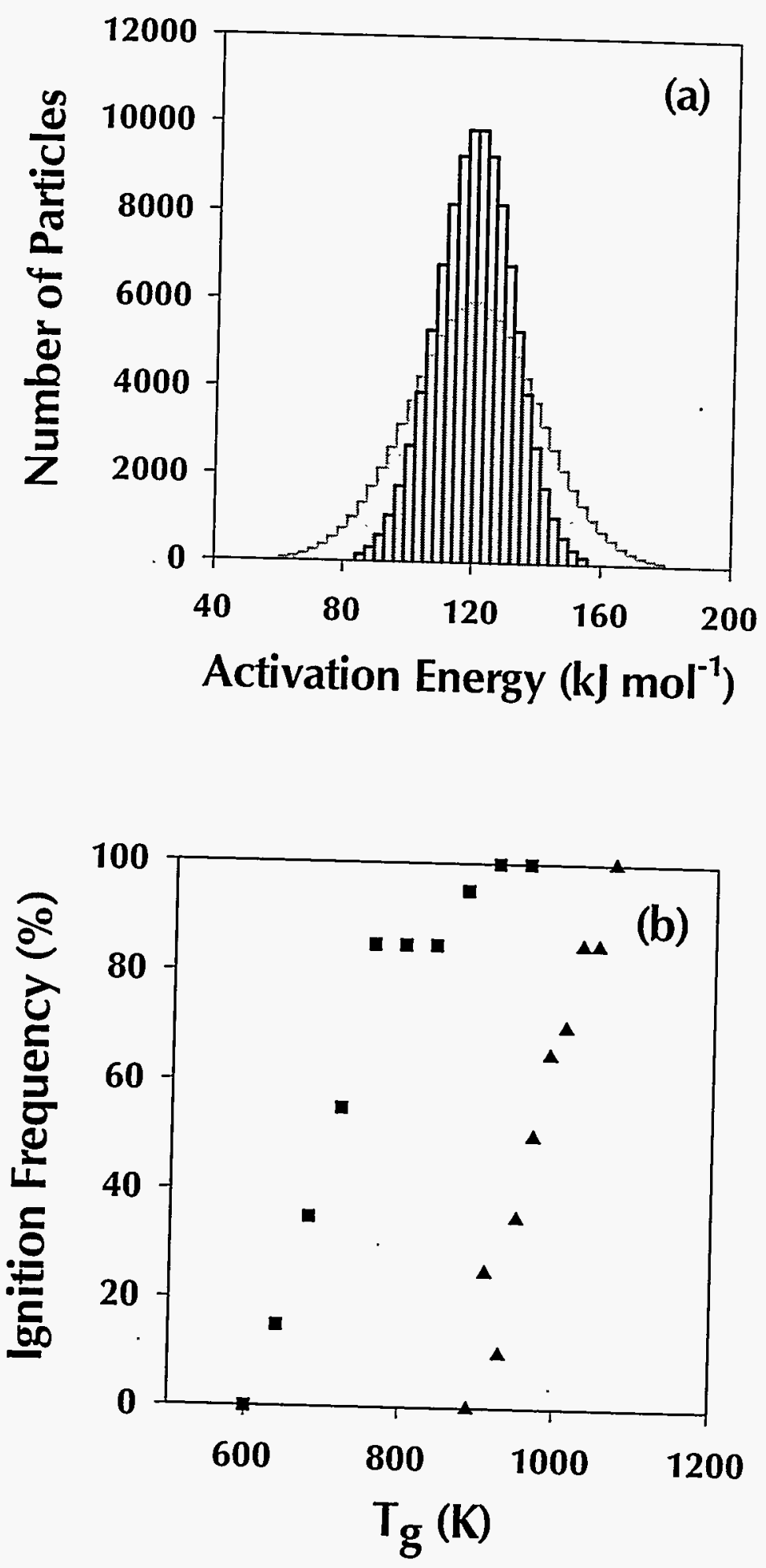

Figure 5 


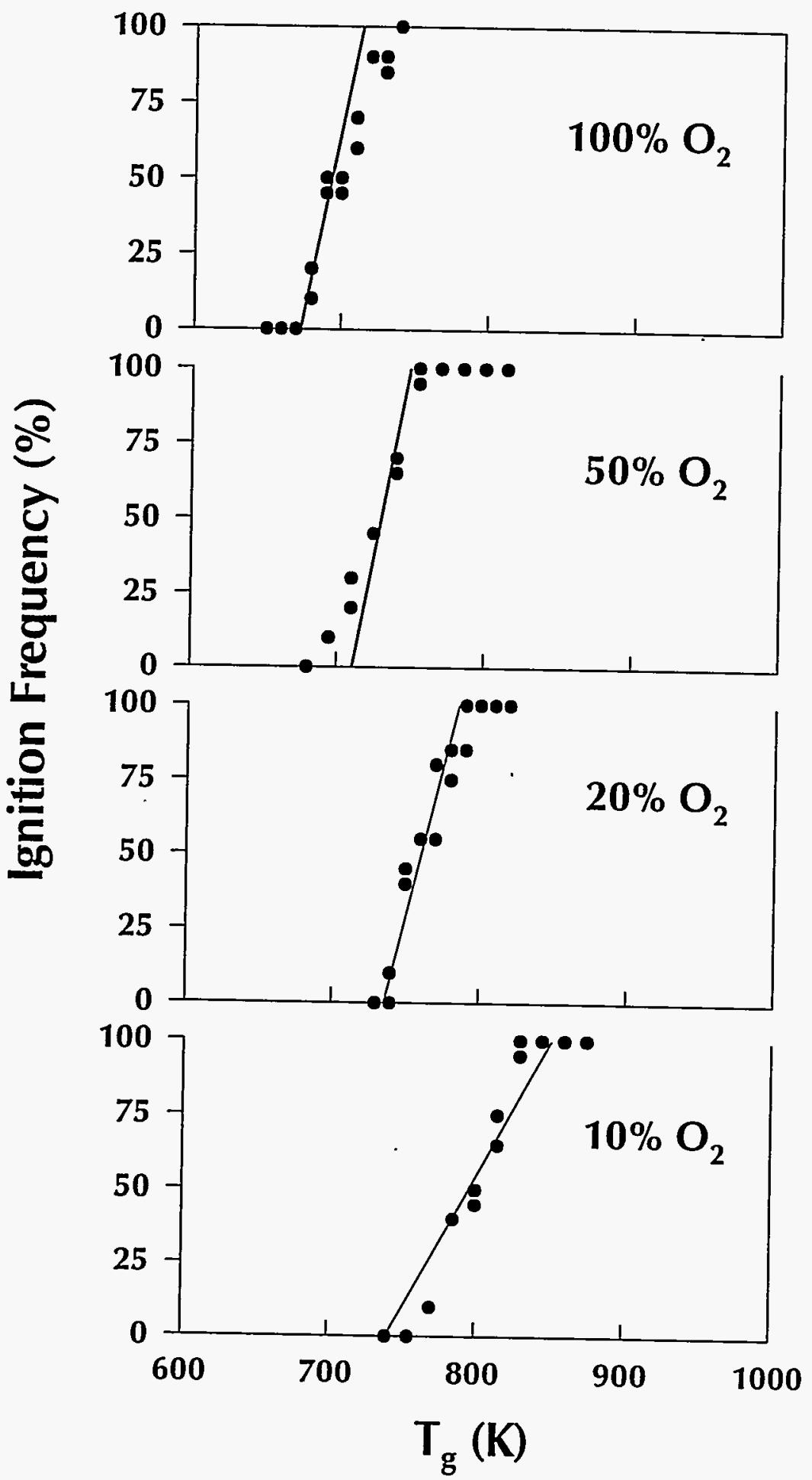

Figure 6 


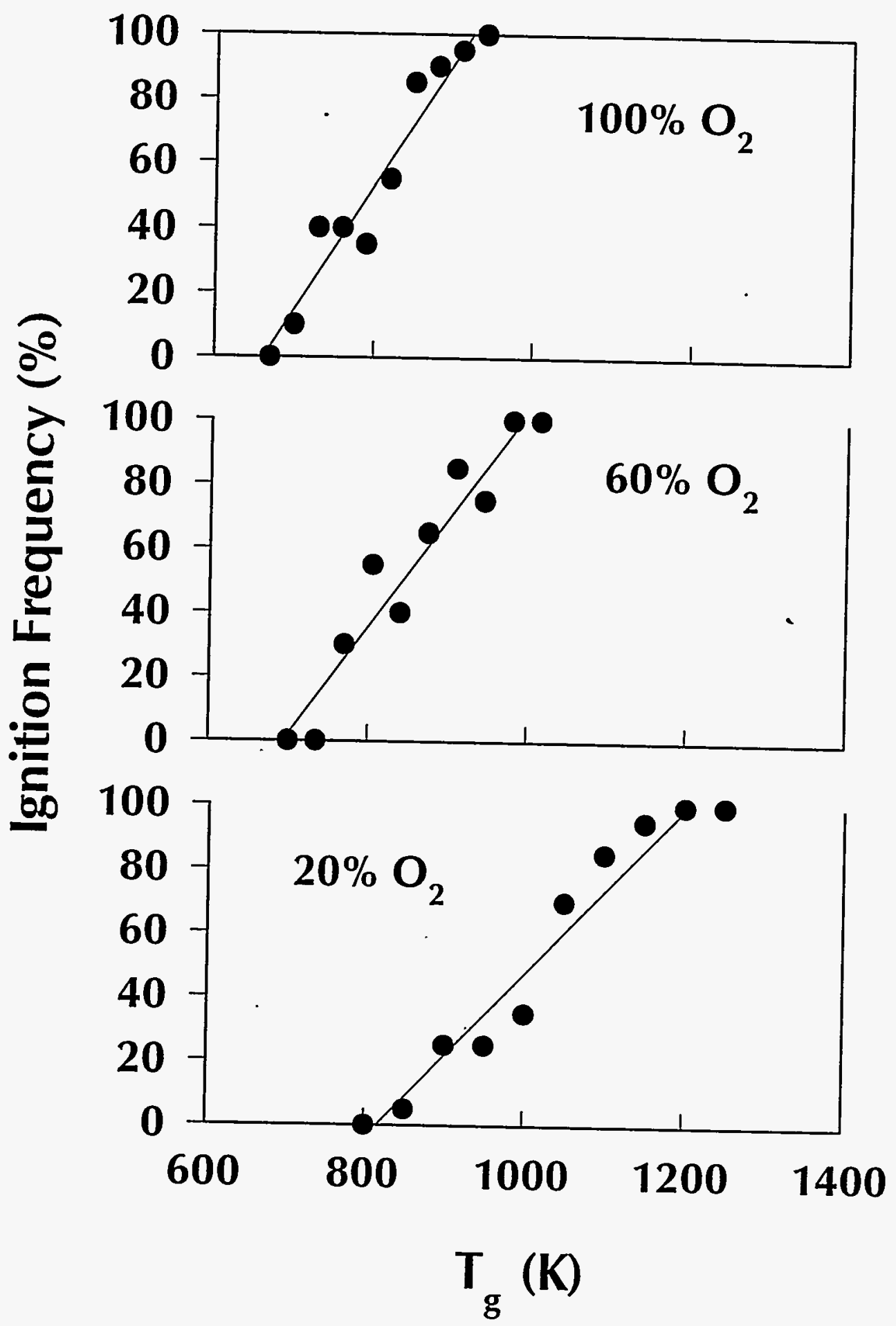

Figure 7 